\title{
$\operatorname{arCOS} D E S I G N$
}

\section{Design de Moda Brasileiro - uma abordagem da cultura material}

Sheila Gies (WelfenAkademie Braunschweig, Alemanha)

sheiladesign@hotmail.com

Salzdahlumer Straße 160, 38126

Braunschweig, Alemanha 


\title{
Design de Moda Brasileiro - Uma Abordagem da Cultura Material
}

Resumo: Este artigo apresenta considerações sobre o design de moda brasileiro contemporâneo como evidência cultural. A metodologia para a pesquisa primária é o estudo de caso único com abardagem da cultura material, com coleta de dados de um vestido de autoria de Karlla Girotto pelo método de Jules Prown e entrevista. Os resultados mostram como os elementos textura, forma e cor do design em análise incorporam e evidenciam o fator humano-cultural brasileiro.

Palavras-chave: Design de moda brasileiro, cultura material, Jules Prown, Karlla Girotto

\section{Brazilian Fashion Design - A Material Culture Approach}

\begin{abstract}
This paper presents considerations on contemporary Brazilian fashion design as cultural evidence. The methodology for primary data collection is a unique case study using the material culture approach to examine a dress by Karlla Girotto, using the method developed by Jules Prown and interview. The results show how the design elements texture, shape and colour embody and express Brazilian culture aspects.
\end{abstract}

Key Words: Brazilian fashion design, material culture, Jules Prown, Karlla Girotto 


\section{Introdução}

A histórica anonimidade do design de moda brasileiro tem sido desafiada já há algumas décadas. Pode-se citar nomes como Alceu Penna e Zuzu Angel dentre os mais significativos precursores de uma moda com preocupações de imprimir características brasileiras. Nos dias atuais Lino Villaventura, Ronaldo Fraga, Alexandre Hertchovitch, Reinaldo Lourenço, Melk Zda, Karlla Girotto e outros têm tido destaque da mídia nacional e internacional como criadores brasileiros, num cenário antes voltado quase que exclusivamente à Inglaterra, França, Itália e Estados Unidos. Além das principais São Paulo Fashion Week, Rio Fashion Week e Semana de Moda Casa de Criadores, há semanas de moda em quase todas as capitais e em algumas cidades do interior, posicionando o Brasil no quinto lugar no cenário mundial da moda. Igualmente significativo é o crescimento dos cursos de moda: desde o primeiro em 1986, o Brasil é hoje o país com mais cursos de moda do mundo (Fraga, 2011), uma mudança que tem fortalecido a criatividade e a qualidade da moda que é produzida no país, por brasileiros. A questão é, então, o que há nessa moda que a faz uma moda brasileira. ${ }^{1}$

\section{Abordagem metodológica}

Este estudo adota a cultura material como metodologia de pesquisa principal. Cultura material se refere ao corpo material e às estruturas produzidas por um povo, e também à idéia de que os valores, as crenças de um povo estão aí expressas. Como estudo, é o processo de descoberta, através de objetos, dos valores de quem os fez ou usou (Schiffer, 1999). Material se refere ao conteúdo em estudo, e o entendimento da cultura o alvo do estudo (Glassie, 1999).

A coleta de dados foi feita pelo método de Jules Prown. Derivado da cultura material, o método sugere uma forma particular de análise de qualquer objeto como evidência cultural e não apenas como ilustração. O objeto em análise é um vestido de autoria da designer brasileira Karlla Girotto, coleção de julho de 2003, escolhido aleatoreamente entre os itens disponíveis.

Os resultados desta análise apresentam aspectos culturais brasileiros expressos através do design de moda, uma nova abordagem ao estudo da cultura contemporânea brasileira e do design de moda. Apesar de dispor do estudo de um caso único, o valor deste estudo está baseado na premissa de que objetos feitos ou modificados pelo homem, de forma consciente ou inconsciente,

1. Este artigo é parte da pesquisa desenvolvida pela autora como candidata ao título de PhD pelo Departamento de Design de Vestuário e Tecnologia da Manchester Metropolitan University, UK, obtido em 2010. 
refletem, direta ou indiretamente, as crenças dos indivíduos que fizeram, compraram, encomendaram ou utilizaram tais objetos e, por extensão, os valores da sociedade da qual fazem parte (Prown, 1982). Dados primários complementares foram coletados através de entrevista com a designer Karlla Girotto e considerados em relação ao seu contexto histórico e contemporâneo. Devido ao volume extenso das informações coletadas, sua apresentação é aqui feita de forma sucinta.

\section{Cultura Material}

Cultura material, como estudo, é o processo de descoberta, através de objetos, dos valores de quem os fez ou usou. Foi durante a década de 1970 e 1980 que objetos começaram a ser vistos como parte de mundos sociais, e desde então esse campo tem se desenvolvido significativamente.

De acordo com Glassie (1999), o estudo da cultura material usa objetos para abordar o pensamento humano em ação. Tal estudo provém uma abordagem acadêmica multidisciplinar para a análise de diversos tipos de objetos, possibilitando expandir ou adicionar ao corpo de conhecimento já existente. Miller (1998) afirma que a cultura material, o objeto, é um meio concreto pelo qual as contradições de conceitos gerais, tanto o particular como o global, são resolvidos na prática da vida diária. Não é apenas constituída pela etnografia, e se mantém eclética em seus métodos. Abordagens da história, arqueologia, geografia, design e literatura são contribuições igualmente aceitáveis.

De maneira geral, a expressão cultura material se refere a artefatos, corpos materiais e estruturas produzidas por um determinado povo. Esse termo parece contraditório em sua composição, uma vez que "material" tem propriedades físicas, é associado ao pragmático, prático e substancial, enquanto "cultura" (Jenks, 1993), refere-se ao espiritual ou mental, conjunto de valores, abstração, conceitos e ideias. Entretanto, o termo cultura material tem a vantagem de resumir o que pode ser conhecido sobre uma cultura através do que pode ser percebido pelos sentidos. De acordo com Bourdieu (1977), a relação entre objetos e a mente é que estes são o resultado tangível de como a mente trabalha.

O termo cultura material é também aplicado à ideia básica de que as crenças, os valores de uma determinada comunidade ou sociedade, em um determinado tempo, passado ou presente, são expressos através do corpo material de objetos produzidos por seu povo. McCracken (1990) afirma que as roupas, transportes, alimentação, por exemplo, servem de meio para a expressão de significados culturais de acordo com a forma que nosso mundo tem sido constituído. Então, pode-se afirmar que todo design é cultura material, mas nem toda cultura material é design. 
O design de moda, como produto e processo, tem particularidades que não são completamente compartilhadas com outros objetos do cotidiano. Uma das diferenças mais óbvias é que as pessoas vestem a roupa, e esta permanece em contato direto com o corpo, é parte da apresentação da pessoa como indivíduo no seu contexto social e, por causa disso, a sua capacidade de tornar públicos os sentimentos e valores de quem as veste e de quem as observa é imensa, possivelmente mais do que qualquer outro objeto. As roupas estão sempre em evidência devido à sua constante exposição. São as roupas que provêm, ao primeiro olhar, uma indicação da posição social de quem as veste, como notou Thorstein Veblen (1857-1929), um dos teóricos pioneiros do estudo da roupa como indicador de status. Existe uma integração entre o material das roupas e a esfera social. Como afirma Miller (2005), a classificação das roupas em tipo, fibra, tecido, forma e produção não é oposta, mas parte da sua consideração como um aspecto do engajamento humano e cosmológico. A moda é o meio mais importante de demonstrar características sociais e valores pessoais. É o que torna a vaidade humana em estética individualizada.

\subsection{Cultura Material e estudos históricos da moda}

Ao analisar uma roupa, inicialmente, é possível obter certas informações sobre quem a usou: medidas básicas como cintura, busto, quadril, ombros ou comprimento total podem dar indicações de formas do corpo. Uma observação mais cuidadosa pode revelar sobre a idade, mesmo que não exatamente, mas é possível pelo menos ter uma idéia da faixa etária. Pode-se fazer considerações sobre o gênero, já que na maioria das culturas a roupa masculina difere da feminina em formas, tipo de tecido, cores, detalhes ou acabamentos. Além destas informações, pode-se ter uma ideia do status e, em uma certa extensão, pode-se ter uma noção de hábitos de higiene, da ocasião social em que foi usada, e ainda a ocupação, caso a roupa seja um uniforme (Dant, 1999). Mesmo alterações feitas em uma peça podem revelar diferenças de tamanho entre quem vestiu e o tamanho considerado regular em determinada época. Alterações podem também ser reveladoras de atitudes em relação à própria roupa, tais como o quanto da área do corpo é coberta, ou revelada, e as conotações aí envolvidas.

Se observações mais acuradas recaem sobre o design da roupa, mudando o foco de atenção do usuário para quem a produziu, as habilidades e qualificações do designer podem também ser avaliadas, incluindo o que o designer considerou importante o suficiente para ser parte da peça, um potencial para expressão de valores culturais (Prown, 1980). Vestuários históricos podem ser vistos como mais significativos para a compreensão de valores compartilhados no contexto cultural e não simplesmente de quem usou a roupa em 
determinado tempo e lugar (Taylor, 2002). Embora tais informações sejam válidas, é preciso considerar que podem não ser completas.

Taylor (1998) cita Fine and Leopold (1993), que argumentam que a abordagem da cultura material no estudo da moda é uma prática de registro totalmente descritiva, defendendo o estudo histórico da roupa mais pelo seu aspecto de consumo do que por seus detalhes, tais como um babado. Entretanto, Taylor argumenta que não há como estudar o contexto de consumo sem ser através da decodificação de valores culturais encontrados em detalhes. Essa é uma consideração plausível, uma vez que tais valores incorporados são também valores compartilhados (Prown, 1982).

A escolha de cada elemento usado na construção de uma roupa é, além de um indicador econômico em potencial, uma evidência do uso de tecnologias necessárias para a definição de cores, de tecidos, de materiais acessórios. O uso da tecnologia pode também ser observado no que se faz necessário para a desenvolvimento da peça, a sua construção em si, incluindo a qualificação profissional necessária, o custo operacional, maquinário, dentre outros. Miller (2005) declara que a percepção dos sentidos - como as roupas são sentidas por quem as usa, e sua estética - como se apresentam - são a fonte de sua capacidade de objetificar mito, cosmologia, moralidade, poder e valores, enquanto instâncias sociais são visualizadas e compreendidas. Vivienne Westwood (McDermott, 1999) afirma que é possível dizer o que quer que se queira através da roupa. Portanto, se uma roupa é apropriadamente examinada, é possível que se obtenham informações significativas sobre sua mensagem não-verbal.

A preocupação a respeito da abrangência da cultura material em consideração à moda histórica ou contemporânea contribui para o potencial do que pode ser compreendido quando se examinam designs de qualquer cultura. A metodologia da cultura material, em geral, tem sido alvo de estudos em seu conteúdo e validade como ferramenta de pesquisa. McCracken (1990) argumenta que abordagens de estudos de valores culturais de objetos devem considerar que os significados culturais incorporados e comunicados por objetos tem uma qualidade móvel. Tais significados culturais estão em constante fluxo para e de vários locais no mundo social, auxiliado pelos esforços individuais e coletivos de designers, produtores, profissionais de marketing e consumidores. Devido a tal mobilidade, o autor também considera que, depois de um tempo, os valores materializados no objeto e os valores de quem usa podem ser diferentes, talvez até opostos, devido à natureza dinâmica das mudanças da cultura que indivíduos, produtores e usuários, compartilham. Da mesma forma, tais valores têm uma essência volátil e, consequentemente, não é possível predizer quando, como e por quanto tempo o fluxo de valores do objeto vai acontecer. 
Jules Prown (1982) também identifica diferentes tipos de valores: o que é intrínseco, que reside no objeto enquanto seu material continuar valioso e, mais variáveis, os valores que serão agregados pelas pessoas que originalmente fizeram ou usaram o objeto. Um aspecto relevante é o gosto ou, mais especificamente, a mudança do gosto ao longo dos anos. Embora McCracken e Prown não se refiram diretamente à importância do registro do tempo em que o objeto é criado ou analisado, pode-se perceber que diferenças em tempo e valores devem ser registrados devidamente quando o estudo de determinado objeto é empreendido. Em estudos atuais, em particular, o significado original deve ser notado antes que mudanças inevitáveis em valor aconteçam, uma vez que tais diferenças de valor serão sempre relacionadas ou divergirão a partir do valor primário incorporado pelo objeto.

Registrar o significado original do objeto em estudo de uma forma apropriada é mais do que apenas estabelecer e compreender valores culturais revelados em um determinado tempo. É uma forma de prover uma base confiável para análises futuras, quando mudanças certas, mas não ainda especificáveis, acontecerão.

\subsection{O Método de Prown}

De forma suscinta, o método de Prown é composto de três passos: 1. Descrição é a análise do objeto em si, seu caráter visual, seus materiais, dimensões físicas, fabricação, texturas, formas e cores; 2. Dedução - é o registro da interação entre o analista e o objeto, uma experiência sensorial/emocional derivada do que foi possível observar durante o primeiro passo; 3. Especulação - dá-se na mente do analista; é a associação livre de idéias, percepções e imaginação, ponderadas pelo senso comum e julgamento do analista, para a formulação de teorias e hipóteses a serem testadas por evidências fora do objeto (Prown, 1982).

\section{Evidências Culturais}

O design em análise neste estudo é um vestido de autoria da designer Karlla Girotto, parte de sua primeira coleção, julho de 2003, "Um vôo para o escuro", representado a seguir. Paulista, Karlla teve formação profissional no SENAISP e é graduada em Design de Moda pela Faculdade Santa Marcelina. Entre outras atividades, trabalhou na empresa de moda Ellus, participou de edições dos eventos de moda Semana de Moda Casa de Criadores, Fashion Rio e São Paulo Fashion Week. Atualmente assina suas próprias criações e é convidada a ministrar workshops e palestras em universidades e eventos de moda. 


\subsection{Descrição}

$\mathrm{O}$ vestido sem mangas e corte reto tem comprimento total de $124 \mathrm{~cm}$, é feito basicamente de uma tela transparente de algodão com inserções de malha de algodão, pérolas artificiais e fios de lã preta (Figuras 1, 2, 3 e 4). Possui uma capa bordada com pedrarias e acabamento com fita de cetim que cobre parte das costas, costurada sob a gola no decote (Figura 2). A gola, em forma de meia-lua e revestida de pérolas de dois tamanhos na parte de trás, se projeta em forma de V para a frente, é preenchida com flocos de algodão, o que lhe atribui uma configuração cilíndrica (Figura 2). A cor opaca tem aspecto envelhecido, contrasta com o brilho das pérolas e pedrarias, com o preto dos fios de lã e, em menor proporção, com o brilho do cetim (Figuras 1,2 e 3).

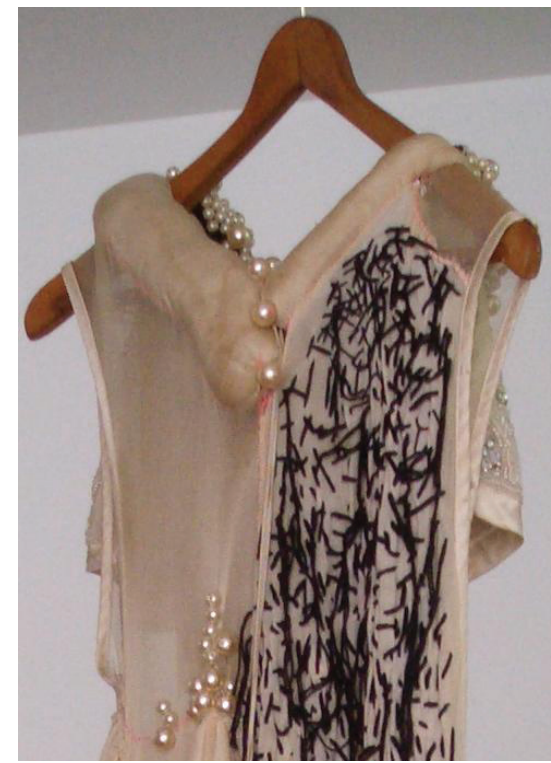

Figura 1. Parte superior da frente

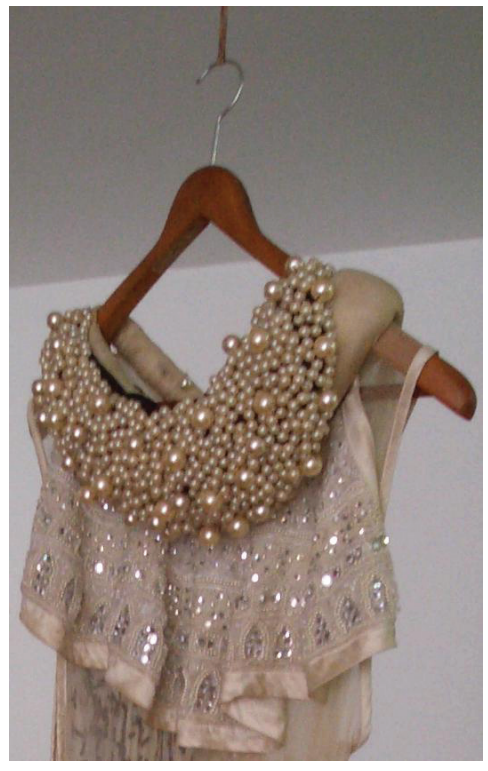

Figura 2. Parte superior das costas

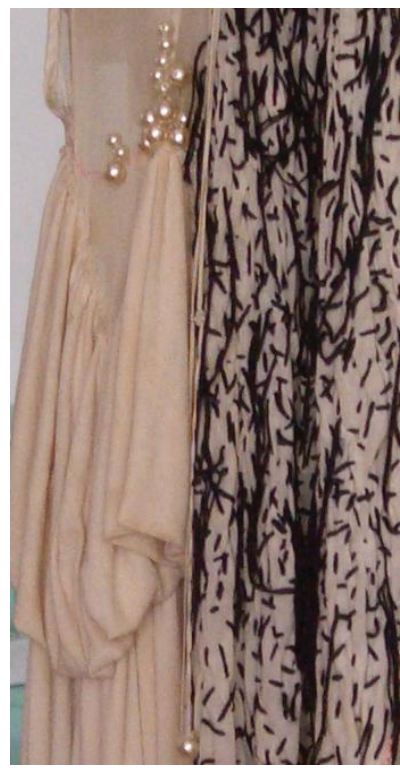

Figura 3. Detalhe frente

\subsection{O Design como Processo}

(Figura 4). Desta forma, as pérolas não são exploradas pelo seu aspecto visual, como é usual, já que estão inseridas em uma dobra de malha de textura fechada. Neste design, na frente, as pérolas contribuem com o seu peso para o equilíbrio com o peso das costas, que está concentrado apenas na altura da linha do decote, na composição da gola e capa bordada com pedrarias. A simbologia da pérola pode se entendida como o valor destas mulheres. Maiores ou menores, são valiosas mesmo quando não vistas; fazem parte do equilíbrio necessário à composição do mundo social. 


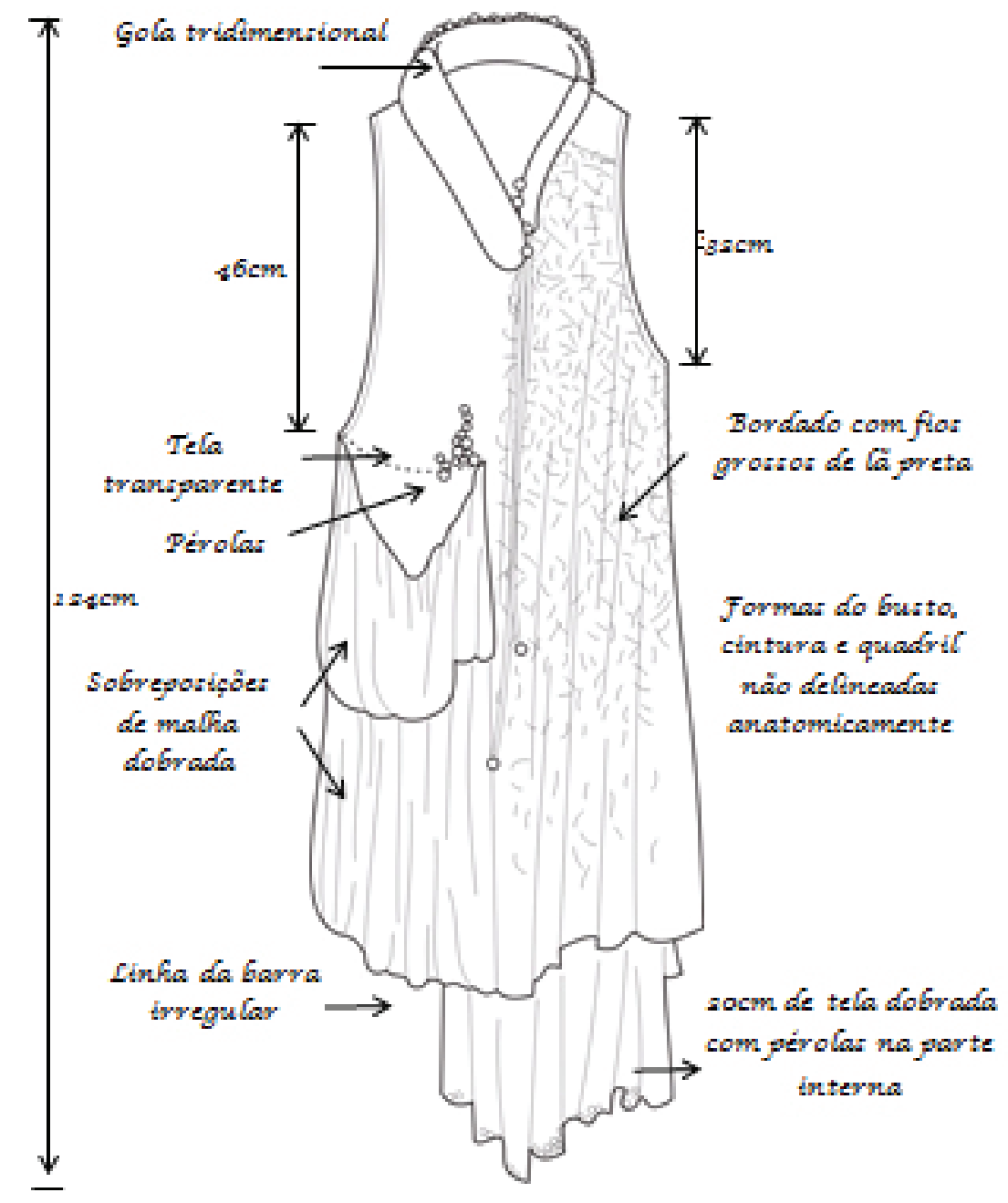

Figura 4. Vestido solto de malha tipo tela transparente e cetim, parte feita à mão e parte feita à máquina - vista frontal

Equilíbrio, de acordo com Davis (1980), é um dos princípios do design que provê a sensação de distribuição uniforme do peso, de regularidade, estabilidade, repouso. Nesse vestido, o equilíbrio é tomado literalmente quanto à distribuição do peso e medidas dos materiais, e não apenas quanto à sensação visual que o resultado dessa distribuição poderia provocar. A adição desses materiais foi feita inicialmente à mão e, posteriormente, algumas partes reforçadas à máquina. Este processo de construção segue o compasso dos sentimentos e pensamentos da designer, uma devoção ao tema que a sensibiliza no momento da criação. 
O que é crucial nesse processo, feito espontaneamente e improvisadamente, é a busca simbólica de balanço entre o mundo masculino e o feminino. Embora domine o conhecimento teórico dos princípios do design, Girotto escolhe deliberadamente desafiar tais princípios, interpretando-os a sua própria maneira, para que a abstração do conceito de desigualdade entre o mundo masculino e o feminino seja neutralizada e equilibrada no design. A espontaneidade criativa privilegia a prática de construção do produto como parte do seu engajamento com o mundo, com o compromisso com o contexto social, que se sobrepõe à teoria, à técnica e ao planejamento. É o idealismo do fator humano que se impõe sobre a formalidade projetual. Esta maneira peculiar de construção é o fator decisivo, uma vez que, como afirma (Forty, 1986), a aparência das coisas, de forma geral, é o resultado das condições em que são feitas.

Pode-se afirmar, então, que a forma particular com que a designer desenvolve suas peças nesta coleção revelam mais que a aparência a elas configurada. Segundo (McCracken, 1990), cultura é a lente através da qual todos os fenômenos são vistos. Embora a falta de equilíbrio entre o mundo masculino e o feminino não seja uma característica apenas da cultura brasileira, pode-se considerar que a forma como Girotto vê, sente e experimenta esta desigualdade no contexto cultural brasileiro e a exprime no design de moda é o que imprime características culturais brasileiras ao design. Isto nos leva a reconhecer que o design incorpora e expressa detalhes muito sutis de uma cultura, que estão além dos estereótipos locais, como o Brasil do futebol, carnaval, samba ou mesmo outros elementos da cultura popular brasileira que são mais popularmente propagados.

\subsection{Cor, Forma, Tecidos e demais materiais}

Neste design, a cor envelhecida é emblemática da superposição entre dois momentos históricos distintos: um atual, quando a coleção é feita e questões do contexto social se apresentam; e o começo do século passado, o tempo referente ao estudo de Freud sobre a neurose que fragilizava as mulheres de sua época. Obtida por tingimento manual, a cor torna-se a materialização de um estado da alma feminina fragilizada, fato que perdura ao longo do século, na visão da designer. A busca por um equilíbrio ideal entre o mundo masculino e o feminino continua latente nos dias atuais, e é pela cor inserida no design.

A busca da cor ideal e sua definição nos indica uma drástica identificação com questões sociais atuais. O sentimento de ver tal problemática se prolongar por tanto tempo e representado no cor é significativo ao ponto da designer fazer manualmente o tingimento do tecido para alcançar o seu tom mais expressivo, o que é explicado por não ter encontrado o tom idealizado em 
produtos oferecidos pelo mercado. Há uma imersão em circunstâncias ideais que resulta em sua concretização no design. Dessa forma, o design é um registro histórico de um aspecto da cultura brasileira contemporânea, quando a supremacia de tendências de modas européias ou americanas relativas à cor são minimizadas ou mesmo desconsideradas em favor da expressão de problemáticas sociais do contexto brasileiro atual.

A forma, onde predomina a assimetria, ignora com veemência as curvas típicas do corpo feminino. As cavas profundas diferem em comprimento, a barra da frente é irregular e notoriamente mais longa que nas costas. Há uma dissonância também na concentração de detalhes, que são distribuídos em toda a frente e concentrados apenas no topo na parte das costas. Embora essa indiferença quanto às formas anatômicas femininas caracterize a silhueta do vestido, uma forma simbólica de aproximar a distância com o mundo masculino pelas formas retas do corpo masculino, a contradição de permitir a visualização quase total do corpo feminino através da amplidão das cavas e transparência do tecido provoca um impacto ainda mais intenso ao destacar a vulnerabilidade com que a mulher é exposta e indefesa diante de sua condição.

Os tecidos, escolhidos de forma a incorporarem o conceito de fragilidade e o que pode ser visto através ou não, seguem coerentes com a abstração dos estudos de Freud, e materializam a constante do contraste ideológico do gênero. Girotto não tem preocupação com tecidos ditos "inteligentes", de alta tecnologia, e faz suas escolhas privilegiando o toque, a sensação que o tecido provoca ao ser manuseado e, portanto, ao ser usado. As sensações que provocam é também o que orienta a escolha de materiais alternativos, os não-tecidos. A exclusividade, tão valorizada no mundo da moda, é ignorada para que seja estabelecido o valor que é possível ser dado ao comum, no dia-a-dia. Nesse estágio de planejamento do design, as escolhas de materiais chegam a incorporar a própria identidade cultural e econômica nacional, como é possível perceber pelas palavras de Girotto: "Eu ainda vou à 25 de Março escolher meus tecidos. A gente precisa assumir quem a gente é”. A designer confere ao tecido e ao local onde é comprado a autenticidade de ser, o poder do senso de pertencer, assumida e responsavelmente, ao povo brasileiro. O design torna públicos os sentimentos, ideais e valores de Girotto.

Além disso, os materiais que compõem o design foram escolhidos não por seu aspecto visual, mas por seu peso e suas medidas literais. Embora tais materiais (tela, malha, fios de la, pérolas) pareçam desconectados pelo contraste predominante de sua composição, brilho, textura, cor, forma e distribuição espacial, existe uma integração entre estes e a esfera social. Constata-se então o que foi observado por (Miller, 2005), que a roupa não é oposta a, mas parte de sua consideração como um aspecto do engajamento humano e 
cosmológico. Para que se compreenda melhor esse engajamento, neste caso específico. Como informado pela designer, "Um vôo para o escuro", a coleção da qual este ítem faz parte, faz uma referência aos estudos de Freud sobre as mulheres fragilizadas, histéricas e neuróticas do início do século passado. A apresentação da coleção é uma narrativa constituída de duas partes: uma rígida, a masculina; e uma frágil, "quase louca”, que é a feminina, referente à tentativa destas mulheres de atravessarem "o muro" do mundo masculino.

\section{Conclusão}

Como apresentado no início deste artigo, a abordagem da cultura material, como estudo, viabilizou a descoberta de questões culturais denominadamente brasileiras, que expressam valores estéticos adquiridos e controvérsias sociais de gênero vivenciadas no contexto brasileiro. É o pensamento da designer quando o vestido foi planejado e executado que se torna tangível no design, e certamente expande o corpo de conhecimento já construído sobre o design de moda brasileiro.

Embora a abordagem da cultura material, em especial o método de Prown, permita a construção de conhecimentos significativos sobre a cultura do objeto em estudo, fica também demonstrada nesse estudo a importância de se associar à investigação a entrevista e de se considerar fontes formais de conhecimento para que tanto a pesquisa quanto seus resultados sejam enriquecidos e tenham sua confiabilidade assegurada. A representação gráfica e fotográfica também permitem que impressões pessoais do analista possam ser compartilhadas, além de questionadas, caso o objeto em estudo não esteja mais disponível para um exame minucioso, como indicado pelo método de Prown.

Como considerado de forma geral por Miller (1998), e visto especificamente neste estudo, o design é um meio concreto pelo qual as contradições ideológicas de gênero, tanto próprias de nosso contexto social como de forma geral, são resolvidos na prática cotidiana, mesmo que representativamente. $\mathrm{O}$ design analisado incorpora o fator cultural brasileiro contemporâneo por ser o resultado da canalização das energias e forças determinadas em como a realidade brasileira é vivida em bases diárias, o que não é necessariamente entendido apenas pela caracterização visual do design, mas nos valores a ela associados.

Embora os resultados não possam ser generalizados ao país como um todo, por ser um estudo representativo, acredita-se que estes resultados colaborem para o entendimento da cultura brasileira através da moda que é produzida atualmente no Brasil, por brasileiros. 


\section{Referências ${ }^{12}$}

BOURDIEU, P. Outline a Theory of Practice. Cambridge, Cambridge University Press, 1977

DANT, T. Material Culture in the Social World - Values, Activities, Lifestyles. Buckingham and Philadelphia, Open University Press, 1999

DAVIS, M. Visual Design in Dress. New Jersey, Prentice-Hall, Inc. 1980

FINE, B. and LEOPOLD, E. The World of Consumption. London, Routledge, 1993

FORTY, A. Objects of Desire Design and Society Since 1750. Thames \& Hudson, 1986

FRAGA, Ronaldo, Gabriela, Marília et. al. Programa Roda Viva. 31 de janeiro de 2011. http://www.tvcultura.com.br/rodaviva/programa/1241

GLASSIE, H. Material Culture. Blooming and Indianapolis, Indiana University Press, 1999

JENKS, C. Culture. London and New York, Routledge, 1993

MCCRACKEN, G. Culture and Consumption New Approaches to the Symbolic Character of Consumer Goods and Activities. Bloomington and Indianapolis, Indiana University Press, 1990

MILLER, D. Material Culture Why Some Things Matter. London, University College London, 1998

MILLER, D. Clothing as Material Culture. Oxford, New York, Berg, 2005

PROWN, J. "Style as Evidence”, The Winterthur Portfolio. Vol. 15, p197-210, USA, 1980

PROWN, J. Mind in Matter: An Introduction to Material Culture Theory and Method. The Winterthur Portfolio, USA, 1982 Vol. 17, p1-19

2. Referências em inglês traduzidas para o português pela autora, exceto a referência de Fraga. 
SCHIFFER, M. The Material Life of Human Beings Artifacts, Behaviour and Communication._London and New York, Routledge, 1999

TAYLOR, L. "Doing the Laundry? A Reassessment of Object-based Dress History", in Fashion Theory: The Journal of Dress, Body \& Culture. Volume 2, Issue 4, p337-358, New York, Berg, 1998

TAYLOR, L. The Study of Dress History. Manchester UK, Manchester University Press, 2002

\section{Agradecimento}

Gratitude a Karlla Girotto pelas informações gentilmente fornecidas em entrevista pela autora em 21.12.2005, São Paulo, e disponibilização do design para análise e fotografia. 
Recebido em: 05/06/2013

Aceito em: 01/10/2013

\section{Como citar}

GIES, Sheila. Design de Moda Brasileiro - uma abordagem da cultura material. Arcos Design. Rio de Janeiro: PPD ESDI - UERJ. Volume 7 Número 2 Dezembro 2013. pp. 113-127. Disponível em: [http://www.e-publicacoes.uerj.br/index.php/arcosdesign]

\section{DOI}

10.12957/arcosdesign.2013.12186

\section{(C) $\mathbb{0} \Theta($}

A Revista Arcos Design está licenciada sob uma licença Creative Commons Atribuição - Não Comercial - Compartilha Igual 3.0 Não Adaptada. 